\title{
Future Geosciences
}

\section{Dr. B.P. Radhakrishna}

These Editorial pages of the Journal of Geological Society of India were decorated by the sage conversations and writings of Dr. B.P. Radhakrishna (BPR). An intellectual colossus in Geosciences, BPR wrote extensively on contemporary themes, celebrated people for their contributions, and educated readers on emerging issues and paradigms in science. He wrote, frankly, fearlessly and without prejudice on almost all aspects of national interest and on themes where science / scientists had a role to play.

I was therefore hesitant to fill the same space, once occupied by a truly erudite and unparalleled persona. At the same time however, I felt tempted, as this invitation was a once in a lifetime opportunity to pay my reverence to BPR by sharing some of my anticipations in geosciences.

My first meeting with BPR was in 1990 during a meeting organized by him and Dr. K.R. Gupta, DST. In this meeting a few of us below the age of 40 years were invited to articulate our vision on Future Geosciences. Though we met only once thereafter, I often received his mails asking me for some details or advice on what a paper meant and what more could be done. His hand-written letters were short, crisp and direct. He also kindly published our book on the Thar Desert.

I feel grateful to the Geological Society of India and its President, Prof. H.K. Gupta for the invitation and the honor to tread on the very paths of BPR by writing in these pages. Prof. K.V. Subbarao shared an excerpt from a BPR editorial and I quote, '...Many burning problems of our time - water, environmental degradation, evils of urbanization and others are discussed freely and frankly in these editorials... Love for my country and an urge to work without any expectation of reward has kept me going'.

In the following, I present some of my thoughts on Future Geosciences in a larger context of the overall debate on the trust between science and society, on the value of our science; all of this, accentuated by the experiences of COVID-19. I discuss as to how, the geosciences could provide meaningful services to the society.

\section{Science and its Social Context: The Issues of Trust}

Science today is at cross-roads, with a distinctive trust-deficit between its practitioners and stake holders, the society. This has occurred despite the fact that, the totality of comforts and the security of food, water, energy and other resources are all at level that is unprecedented and, that these have all been provided by science-based innovations. Growing population and technology accelerations have altered the narrative of relationship between science and society. Till yesterday, science and society co-existed without expectation from each other.
Most of us, grew up in the days with the leitsatze of free play of free intellect by Vannewar Bush. With time, products based on scientific discoveries made lives comfortable, ensured security and thereby the impact of science was felt by the society. Technologies based on scientific innovation pervaded lives as ether. Increased information, enhanced comfort and rapid communications gradually raised expectations of continued delivery from science and that too, in real time. And, the society also began having views on science. Prediction of rainfall or cyclones or earthquakes are examples, where each forecast is censured widely for its successes or failures and, instant judgment on science and scientists are pronounced.

This missing trust has initiated debates about who should be managing science - the scientists or the society, through its representatives. The argument put forward is that being a party to scientific process, scientists cannot objectively evaluate their science and a third party evaluation is called for. This encroachment on science/education management space is currently happening. Recent developments in geosciences and medical sciences, both at the national and international levels, provide ample indications. The 'perceived' failure of scientists in anticipating the COVID pandemic and inadequacies in properly advising on handling it, for whatever reasons, is an example of such an encroachment. Consequently, the science management space is being increasingly appropriated by nonscientists and pseudo-scientists, willing to compromise the long term science based solutions to facilitate short term gains personal or political.

In this pandemic, the society has constantly experienced deficiencies of reliable information. One often found conflicting statements on the science of the pandemic, its management and even the vaccination. Academia at each level could not measure up to the challenge of communicating science, effectively and timely. And, to add to their woes, has been a deluge of research publications on COVID - 19 over the past few months. Their numbers make it humanly impossible to synthesize them for global good. Much of this science has possibly been opportunistic, driven more by the anxieties for rapid fixes and solutions, buttressed by relaxed funding and ease of publications.

The copious volume of science on the Global Change has been no different. This is also buttressed by the pressure of publications and the ease of funding for a globally acclaimed, bandwagon science. There is a clear message for us here - to self-assess the value of the science that we do and its significance for the real world and for advancing the true frontiers.

Expectations on either sides have been accentuated. Today, science and its practitioners seeks more support for research and the society demands more science per dollar in return. In ancient times, the knowledge bases of an individual and that of 
the society were similar - largely based on local knowledge/ information/data. The decision making was based on personal experience. Increased communication, travel and technology acceleration led to an exponential divergence between the knowledge bases of individuals and the global society to the extent, that at present, most decisions at individual to institutional to national level are based on incomplete/designed information, half-baked knowledge and, invariably factors other than science play a role. Fake news, manufactured doubts and doctored information are ubiquitary. It is here that the science and its serious practitioners must play a role in translating results from rigorous science into actionable prescriptions and reliable information packages. Anticipated catastrophe of climate change will need an active role and secured interpretations from geosciences.

\section{Priorities, Style and Introspection}

The keenness of society for products from science has led to a misplaced cultural focus on applied research with the mantras of innovate, patent, produce and prosper. Till recently, technology was subsumed in science but now science stands subsumed under technology. Most times now, it is the technology that drives the science priorities. This has led to a cultural shift with a diminishing emphasis on basic science that by definition is devoid of instant glamor and is a pursuit that does not provide rapid fixes. It is appropriate to remind that basic science will remain the pace maker of future technologies and innovation. Therefore, the future trajectory of science will have to be a judicious mix of basic and applied components. Basic science would ensure creativity and develop foundations to spawn meaningful applied science. Innovations occur only in an overall ecosystem and edifice of competent teaching, basic research, and diligent minds, free of limitation of their ecosystems.

The history of science is replete with examples as to how seemingly disconnected discoveries led to new technologies. Nature is difficult to predict and therefore society needs to keep servicing, nurturing and developing all forms of knowledge with equal fervor. Microbiology till recently was of subordinate importance, but post COVID-19, it now occupies a near center stage. An important lesson here for science management is that there is nothing immediate or more/less important in science, and every aspect that explores new ideas/paradigms/concepts is important for its potential future use. This would call for a trust, a vision, some hope and a faith in the scientific process.

That said, there is also a need for introspection. We as a community need to carry out an assessment of the value and contemporaneity of our science. A continuing self-evaluation and contemplation on whether the science we do is incremental, data gathering type or otherwise, is needed. Often lots of data are generated, but the next step of using these data for planning/ policy is not taken. In the context of Global Change research, there is a need to convert laboratory data to usable products for modeling and planning the planets' future. We clearly need an honest self-audit.
We must also ensure that every research program should have a 'sell by date' to facilitate newer ideas/paradigms to emerge. In the German system, research programs/centers are regularly closed to facilitate newer activities to emerge.

As for our priorities in science, I quote BPR, "there is no denying that the bulk of Indian research is fashioned after the western model.... the problems selected are those currently in fashion in the western laboratories and very rarely has scientific enquiry been directed towards solving problems affecting India and its people.... He commented on vision documents for Earth Sciences, 'are these priority area of research: What are we really trying to achieve? Do they in anyway contribute to the welfare of our people....'. And, as a community we need to pose this question to ourselves on a daily basis.

\section{Geosciences: The Indian Narrative}

For geosciences, India has all of the geo- phenomena, processes and records encapsulated in a single political entity. It comprises: some of the very old rocks, high mountains, multitudinous glaciers, the largest foreland basin, mighty rivers, a near exclusive climate system comprising the monsoons and the westerlies, lakes, lagoons, mangroves, deltas, deserts-hot and cold, impact craters, volcanoes, open ocean and the closed Bay of Bengal. And, to add to all of these, is the substantive human impact and a complex socio-cultural-ecology, knowledge systems and practices.

With such riches of the nature, culture and knowledge systems, the moot question is, why does Indian science not occupy a stage of leadership in the conceptual space and provide meaningful prescriptions to the society. And, what could and should be the modus operandii by which, that Indian research efforts can be upscaled so that the trust of the society, that supports our research can be retrieved, retained and maintained.

History is harsh, for it provides a space - time integrated appraisal of the events and the performance of societies/groups in the past. We are also aware that in nature, the landscapes are sculpted by extreme events. Analogously, admirable advances in the scientific landscapes have required delta functions of excellence. In both these examples, though the extremes play an important role in sculpting landscapes - geological or intellectual; these occur only when an appropriate ecosystem and environment gets created. Thus, until a community can and is empowered to work at a highest level, constantly and consistently, its contribution does not get recorded by history. A favorable ecosystem that facilitates excellence, is a necessary condition. In Africa, bonsai crocodiles, are created by keeping offspring of normal crocodiles in limiting environments of space and resources. We need to guard again creating bonsai scientists, by limiting their academic ecosystem through restrictive funding, excessive administrative hurdles and daily accountability amounting to micromanagement. A lot needs to change in the way we handle and nurture our younger colleagues and institutional leaderships need to proactively ensure that their 
colleagues work in the most conducive and enabling environments. We have a message here and the community needs to decide, if it wishes to have a page or a paragraph or a word in the history of Indian science, whenever it is written.

Geoscience now is truly an interdisciplinary and an academically alluring science. Excellent competence exists in India, but the, vision, synergies and the appetite to upscaling are not visible. I repeat what I said above, a radical change in our ethos, the ecosystem, the style and the work culture is called for. We also need to graduate from individual centric science to a mission mode, systems driven approach with well-defined time lines and deliverables. Large data bases of varied kinds are the need of the hour and we need to augment our capacity to generate these. It is my conviction that with the exceptions of theoretical research, individual geoscientists cannot deliver meaningful results, simply because of the complexity of the Earth system and, the processes and feedbacks in it. There is also, a need of significance statement for each study carried out through public support. The significance statements permit a layman to comprehend the basic message of the work being reported. And, such an effort to communicate science, will, undoubtedly sharpen our scientific focus.

\section{Future Geosciences}

Geosciences impact people on a day to day basis - be it water, food, energy, hazards, resources and this makes it necessary to include social dimension in geosciences. To quote Prof. Naomi Oreskes from her article, How Earth Science has become a Social Science, ... "major questions in Earth science research today are not matters of behavior of physical systems alone but of interaction of physical and social systems. Information and assumptions about human behavior, human institutions and infrastructures, human reaction and responses, as well as consideration of social and monetary costs play a role in climate predictions, hydrological research and earthquake risk assessment. The incorporation of social factors into physical models by scientists with no training in humanities and social sciences creates grounds for concerns as to how well such factors are represented and thus how reliable the resulting knowledge claims might be".

There is a need for a National Vision with a regional perspective nested in global best practices. This vision must be created through a bottom-up effort and with engagement of all stake holders viz. science, teachers, society and policy makers. Anticipated resource crunch would necessitate prioritization and development of key mission mode programs around specific scientific questions, both in basic and applied domains and with sufficient room for individual excellence to grow alongside. By implication, these questions will have to be eminently futuristic, scientifically exciting and socially relevant.

For Earth Surface Science, a discipline closer to my experience, some of the action items are presented below. Most of the points that I make will also be applicable to Geosciences and other sciences in general. It is my firm conviction that all planned activities on the Earth's surface must be nested in robust geoscience information. While, most of what I say will be obvious to many, a recapitulation may be worthwhile.

1. To develop the Science Vision, the professional geosciences associations ( 25) will need to assume responsibility. In fact, our proposal to create the Federation of the Indian Geosciences Association of India (FIGA) was to create such synergies, enable transgression of discipline and personal boundaries and develop new programs through a bottom-up consultative process. It is hoped that FIGA shall provide a platform for synergy, for new programs and paradigms to emerge. The time is ripe now to fuse individual expertise to create a symphony orchestra of Geosciences.

2. The future geoscience teaching departments would need augmentation and would need to comprise faculty/courses from Physics, Applied Mathematics, Instrumentation, Computer Sciences, Biology, Material Sciences, besides the conventional disciplines. A radical change in geosciences teaching is needed for training students in contemporary geosciences. Thus, a future geoscience student, would, besides geology, learn elements of biology, mathematical techniques and data analytics including the $\mathrm{AI}$ and ML, material sciences and systems analysis in reasonable proportions. We would need to change our teaching to integrative teaching through the concepts of particles, fluxes, time scales and conservation laws. Emergence of research in interdisciplinary areas such as Geomorphodynamics, Geobiology, Geomathematics, Ecohydrology, Eco-geo- morphology, Geo-forensics, Geopharmeceutics, Medical Geology, Molecular Palynology and Paleontology will then be easy.

3. Indigenous development of instruments is a dire need of the hour. I propose that $30 \%$ EMR funds be earmarked for technical developments initiatives to ensure, selfsufficiency, self-reliance and to realize the scale/density of instrumentation with in the resources available to us. There is a need to replicate, our proposal for centers like Ministry of Earth Science - National Geochronology Centre at the Inter University Accelerator Centre, Delhi and create more community hubs that would provide experimental facilities on an equal opportunity basis; without the user having to go through the tedium of maintaining complex instruments and without having to compromise on their IPR. Such centers should also be developing customized instruments as rarely new science emerges from commercial systems. The current craze for acquiring and owning instruments will have to give way to enthusiasm for novel ideas and programs. The use of few wellmaintained national experimental facilities on an equal opportunity basis should be the norm. To me, instruments not used on a $24 \times 7$ basis is a criminal waste of resources and it is painful to see major experimental facilities in India, lying dysfunctional due to lack of internal competence for their maintenance. 
4. Development of systems for real time, autonomous and intelligent insitu measurements of catastrophic events such as landslides and floods using specific position, moisture, temperature, water level sensors for a real time prediction of their occurrence. Recently, Amrita University with the support from MoES, has demonsrated the feasibility of such concepts and these now need rigorous upscaling with geology interface, as major national initiatives.

5. Multiplication of schools for modeling and simulation involving physicists and applied mathematicians. In the areas of quantitative geomorphology and Earth Surface Science, numerous possibilities exist. These are:

a) modeling of flood inundation from rivers based on their geomorphic space for one in a hundred year or one in a thousand year floods and the use of field data, chronology of the flood plain and paleo-flood records to provide maps for safe habitation. Use of remote sensing and sensor networks for simultaneously observing geomorphic events on meter to basin scale are needed for developing basin specific scaling relationships.

b) modeling of urban and nuisance floods due to extreme weather events with hazards accentuated by increasing population, waste water and sea level. In fact, future resilience of urban areas cannot escape geoscience inputs.

c) modeling of inundation patterns from tsunamis under an anticipated rise in sea level and development of optimum evacuation strategies under hazards (earthquakes, tsunamis floods or forest fire) so that on Dday, optimum scenarios are available apriori. The work of Indian National Center for Ocean Information and Services (INCOIS) for tsunami induced inundation forecasts could be used as a template.

d) development of schools to understand, measure and model, the response time of land forms, critical thresholds in their response, the effect of changing vegetation and ecology for landscape and land use planning. Observatory programs to monitor and develop models to identify potential tipping points of strategic geomorphic and ecological systems are needed.

e) similarly research on validation of the response times and style of proxy signal used in paleoclimatology need careful investigation. A synthesis of paleoclimate data to derive regional gradients with an interface with climate modelers is needed.

f) development of an understanding of critical zone/ soil processes and the carrying capacity of various regions under increasing temperature and hydrological extremes, and studies on sustenance of agriculture under these extremes of temperature and $\mathrm{pCO}_{2}$ is called for. This will call for integration of all disciplines. MoES has just approved our suggestion for a National Observatory Program on the Critical
Zone. This is now underway and would need substantive amplification, enthusiastic participation and institutional synergies.

g) understanding the role of biology in geology, ranging from soil processes to bio-mineralization at molecular/ microbial RNA-DNA level is needed. These studies will also include possible role and adverse impacts of a release of new bacteria and viruses from sediments and ice due to climate changes and from disturbances in terrestrial ecosystems and habitats.

h) developing modeling efforts to compute past ecosystem changes using palynological data to inform future ecological changes. These will need considerable modeling effort towards the development of transfer functions.

i) development of scenarios for future townships to host climate change induced migrants. Such migration is inescapable and will need an integration of social sciences, ecology besides the entire gamut of geoscience expertise.

j) modeling and observation on human activities to predict tipping points of eco- and geomorphic systems; development of AI based sensor networks for such studies and,

k) use of AI and ML and other data analytical models to inform research on climate, earthquake science and to detect latent periodicities and thresholds. These however should be nested within sound geological and physics basis.

6. Modeling would need high quality experimental data and towards this, the Indian laboratories would need rigorous data inter-comparison and calibration programs. Inter-comparison on blind samples / standards should be routinely done and formally published. A concerted national program and a repository of national standards with adequate funding is called for to facilitate and create benchmark experimental data in geosciences.

7. Development of crowd sourcing in education and research. It should be eminently possible to use and support local geology departments to prepare stratigraphic logs and other measurement for all the deep trenches dug for the foundations of housing. These would enable development of large scale 3-D regional sub-surface stratigraphy using GIS platforms. The same could range from water quality maps to flood hazard maps. Such documentation would variously inform seismic microzonation to safety from floods and human health, and would serve multiple objectives of training the students, developing their connect with society, and generating useful data for the entire nation in a short time and at a fraction of cost compared to that charged by professional agencies.

8. Similarly, colleges, schools and researchers should be encouraged and supported to develop booklets on roadside geology to ensure conservation of geoheritage and 
develop public interests. The Geological Survey of India with its wide reach can develop such a dedicated program of societal relevance and use it as a vehicle for human resource development and public outreach.

9. Create mechanisms for data and sample repository and archival system. All data and samples acquired using any of the public funds should be archived/curated in a national data and sample repository after a moratorium period of 2 years. To begin with, such a suggestion may appear restrictive but will help all in the long run. I consider that there is real need to create an autonomous center for sample and data archival and curation. Such a center could be jointly nurtured and funded by all ministries and departments dealing with geosciences, directly or indirectly. Recently the Government of India has announced Distinguished Professorships of its Ministries. It will be a win-win situation, if experience of some of the scientists with proven track records are harnessed to develop such centers and in the process, develop a culture of creating new products from existing data through synthesis.

10. Geosciences in India is variously supported by several agencies, such as the Ministries of Earth Sciences, Environment and Forests, Defense, Mines and Water resources; Departments of Science and Technology, Department of Space and Atomic Energy and several others. Each of these Departments and Ministries, have ambitious vision and plans but a synergy among them seems to be missing. An example is the area of Glaciology due to its importance on water security for large areas. Research and measurements are being carried by several groups at varied levels and with varied focus but, one does not see a national level coherence that could deliver a wholesome, integrated set of data for planning in a mission mode. This sub-criticality of departmental efforts needs to mature into a complimentary, national initiative to deliver competent products in real time. One cannot over emphasize the need for institutional synergies where all boundaries and fealties are transgressed for complementarity of expertise, commonality of purpose and a consensus for resource optimization.

11. It is also the time for India to use science for diplomacy and capacity building. I suggest that all the training courses in India be made accessible to the developing world, so that we create a constituencies of good-will through education and training.

12. Finally, one would expect that the National Surveys assume a leadership and an enabling role in developing both the mapping and research paradigms in the country. This will call for a revamping of the manner in which the surveys are led, managed and interfaced with others. Given the scientific competence and resources that exists with surveys, there is an enormous opportunity that is waiting to be tapped.
The discussion above is only indicative and surely several other thoughts, possibly deeper and with more traction would exist. The suggestions above are intended to initiate discussions and introspections for future synergies. The basic focus should be to ensure that science should either inform concepts or provide tangible results of relevance to policy and society.

\section{In Conclusion}

In the milieu of the post COVID-19 era and the stress on the economy that it has unleashed, it is certain that the funding for science will be stressed. This is the time for us to think harder so that despite constraints, we are able to prioritize and optimize our efforts to ensure that science delivery still remains at the highest level.

I will end up with recalling a piece of advice and a quote. The advice that Dr. Vikram Sarabhai gave to a colleague, that to gain respect and recognition, one needs to assume responsibility. Benjamin Franklin said, either write something worth reading or do something worth writing.

For us geoscientists, the time is now to put our act together, for tomorrow, it may be too late. This choice for us, is between gaining respect or being relegated to irrelevance. There is no escape that we develop schools that carry out first rate basic science such that all our applied research is nested within the knowledge at the cutting edge. All our reports/publications should have an explicit significance statement stating their possible policy/societal relevance. This is the time to put all the hats and heads together, create mutual trust with reciprocal respect and large scale synergies to deliver science to the nation, at the highest level.

Acknowledgements: My ideas and thinking on the issues discussed here have benefitted through discussion during decades long interactions with, Prof. R. J. Wasson, James Cook University and the Australian National University and with Prof. R. N. Singh, Indian Institute of Technology, Gandhinagar. I have also benefitted from several vision documents of the National Academy Press, USA and other literature on the www. Prof. D. M. Banerjee, Prof. R. N. Singh, Prof. R. J. Wasson and Prof. H. K. Gupta provided constructive comments on the drafts of this Editorial. This contribution has been prepared during my tenure as DST-SERB- Year of Science Chair Professor.

Soon after this editorial was written, we lost two geoscientists in Prof. K.S. Valdiya and Prof. Nilesh Bhatt. Prof. Valdiya was a colossus in Indian Geosciences and Prof. Bhatt was an emerging young geomorphologist. I recall their impact on my persona and my science with a sense of deep reverence and gratitude.

Ashor Kumar Singhvi

DST-SERB, Year of Science Chair Professor, AMO-PH Division, Physical Research Laboratory,Ahmedabad - 380 009, India E-mail:2aksprl11@gmail.com 


\section{Bibliography}

Flexner, A. (2017) The Usefulness of Useless Knowledge. The Princeton University Press, 92p.

National Academies Press: Landscapes on the Edge: New Horizons for Research on Earth's Surface. www.nap.edu/catalog/12700.html

National Science Foundation, (2020) A Vision for NSF Earth Sciences 2020-2030: Earth in Time, http://nap.edu/25761

Pujari, P.R., Jain, V., Singh, V., Sreelash, K., Dhyani, S., Nema, M., Verma, P., Kumar, R. Jain, S. and Sekhar, M. (2020) Critical zone: an emerging research area for sustainability. Curr. Sci., v.118, pp.1487-1488.

Oresekas, N. (2015) How Earth Science has become a social science. Historical Social Research, v.40(2), pp.246-270.

Radhakrishna, B.P. (2003) Random Harvest - an anthology of editorials. Geological Society of India, Bangalore, 444p.

Singhvi, A.K. (2011) An opportunity to document subsurface sedimentary architecture. Curr. Sci., v.101, pp.135.

Singhvi, A.K. (2018) Some thoughts on future studies in Climate Change and Quantitative Earth Surface Processes in the Indian Context. Climate Change PPF Newsletter, v.III(1), pp.2-6.

Singhvi, A.K. (Ed.) (2020) Floods in Rivers, Origins, Hazards, Floods, and Policy Prescriptions. Indian National Science Academy, 51p.

Wood, W.W. (1997) Fluxes: A new paradigm for geologic education. Editorial Ground Water, v.35(1), pp.1.

Wood, W.W. and Wood, W.T. (2014) Fluxes versus the Frankenstein model of Earth Science Education. Hydrogeology Jour., DOI: 10.1007/s10040-014-1158-5 